\title{
Full-scale laboratory study on distribution of individual wave overtopping volumes over a levee under negative freeboard
}

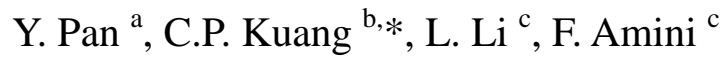

${ }^{a}$ College of Harbor, Coastal and Offshore Engineering, Hohai University, Nanjing, Jiangsu 210098, China

${ }^{b}$ Department of Hydraulic Engineering, Tongji University, Shanghai 200092, China,

Email: cpkuang@tongji.edu.cn

${ }^{c}$ Department of Civil and Environmental Engineering, Jackson State University, Jackson, MS 39217, USA 


\begin{abstract}
Wave overtopping parameters are key parameters in the design of levees and the management of coastal protection. This paper presents the distribution of wave overtopping volume and instantaneous overtopping discharge under negative freeboard. The analysis and discussions are based on the results of full-scale flume tests for a levee section in the combined wave and surge overtopping. Four wave overtopping patterns under negative freeboard were observed. Weibull distribution was used to represent the distribution of individual overtopping volumes and the distribution of instantaneous overtopping discharge. Based on the hydraulic characteristics of wave overtopping under negative freeboard, empirical equations for Weibull factors were developed in the two different ranges of relative freeboard. The new equation gives better estimates of Weibull factors for the low discharge condition.
\end{abstract}

Keywords: Wave overtopping; Negative freeboard; Combined wave and surge overtopping; Full-scale tests; Individual overtopping volume; Instantaneous overtopping discharge 


\section{Introduction}

Wave overtopping on levees is one of the important issues in coastal engineering field. The wave overtopping parameters are key parameters in the design of levees and the management of coastal protection. The most representative overtopping parameter is the average overtopping discharge $q_{w}$, which is used in the design of the crest elevation of levees. Several studies have been conducted on the distribution of the individual wave overtopping volumes under positive freeboard (e.g., Besley, 1999; Franco et al., 1994; Lykke Andersen et al., 2011; Nørgaard et al., 2014; Pullen et al., 2007; Van der Meer and Janssen, 1994; Victor et al., 2012). The freeboard is defined as vertical distance between the still water elevation and crest elevation. A positive freeboard means incoming still water elevation below crest elevation. Fig. 1 illustrates the wave overtopping under positive, zero and negative freeboard and surge overflow.

(a) Wave overtopping under positive freeboard $\left(R_{c}>0\right)$

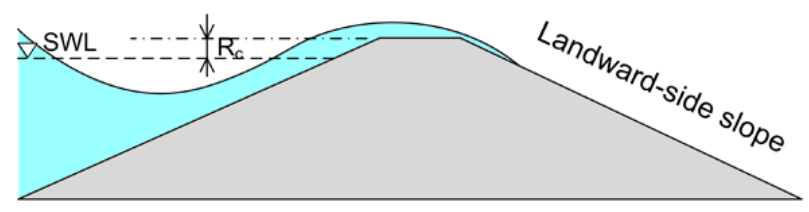

(c) Wave overtopping under negative freeboard $\left(R_{c}<0\right)$

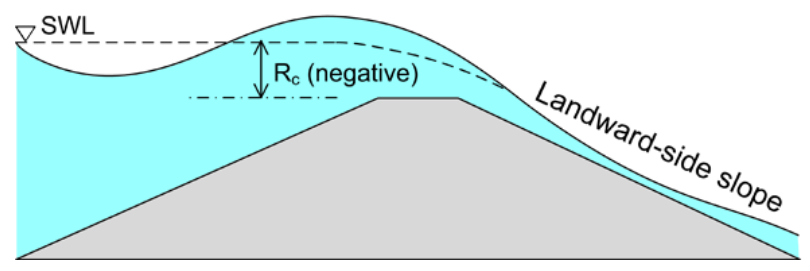

(b) Wave overtopping under zero freeboard $\left(R_{c}=0\right)$

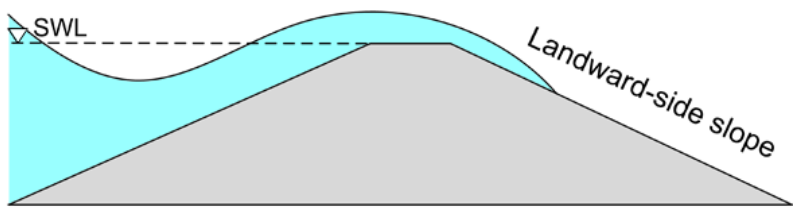

(d) Surge overflow under negative freeboard $\left(R_{c}<0\right)$

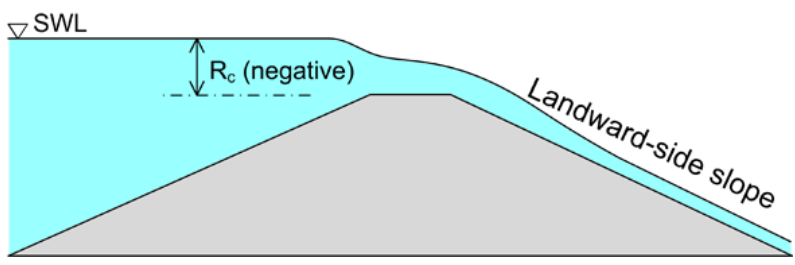

Fig. 1. Wave overtopping under positive, zero and negative freeboard and surge overflow. 
During storm surge, wave overtopping is more dangerous under negative freeboard than under positive freeboard. Analysis showed that during overtopping, the landward-side slope of levees was exposed to significantly higher velocities and much greater erosive forces than the flood-side slope (Hughes and Nadal 2009). The climate changes lead to the sea level rising at an increased rate and storms increasing in intensity and duration (IPCC, 2007), which increases the risk of wave overtopping under negative freeboard. Since hurricane Katrina, wave overtopping under negative freeboard has been studied by several researchers (Li et al., 2012; Li et al., 2014; Pan et al., 2013ab; Rao et al., 2012; Yuan et al., 2014ab). Hughes and Nadal (2009) initially investigated distribution of individual wave overtopping volumes for levees under negative freeboards via a series of 25-to-1 flume tests. Pan et al. (2013a; 2013b) conducted a series of full-scale tests to investigate the hydraulic characteristics of wave overtopping under negative freeboard and the erosion resistant performance of three different levee strengthening system, including Roller Compacted Concrete (RCC), Articulated Concrete Block (ACB), and High Performance Turf Reinforcement Mat (HPTRM).

The analysis and discussions in this paper are based on the measurements and observations of full-scale flume tests (Pan et al., 2013a). Four observed wave overtopping patterns are divided into two categories. In each category, empirical equations were given to estimate the probabilities of occurrence. Results of the full-scale tests indicate that, under negative freeboard, some of the overtopping parameters show distinctly different behaviors over the range of negative relative freeboard $R_{d} / H_{m 0}$ [-] (e.g., $R_{d} / H_{m 0}<-0.3$ and $-0.3 \leq R_{d} / H_{m 0}<0$ ) as illustrated by 
the variation of dimensionless discharge shown in Fig. 2. The goal of this paper is to study the distribution of wave overtopping volume and instantaneous overtopping discharge under negative freeboard in the ranges of $R_{C} / H_{m 0}<-0.3$ and $-0.3 \leq R_{C} / H_{m 0}<0$ separately. Weibull distribution is used to represent both individual wave overtopping volume and instantaneous overtopping discharge. The distribution parameters of the full-scale tests are compared to Hughes and Nadal (2009), and the differences between the results are discussed. New equations are presented for individual wave overtopping volume and instantaneous overtopping discharge to obtain better estimations. Because the tested levee strengthening systems are installed only on levee crest and land-side slope, the levee strengthening systems have little influence on the overtopping pattern, the distribution of wave overtopping volume, and the distribution of instantaneous overtopping discharge. The effects of levee strengthening systems are not discussed herein.

\section{Background}

The probability of overtopping $P_{o w}$ is defined by the ratio of overtopping number of waves $N_{o w}$ and incoming number of waves $N_{w}$ as

$$
P_{o w}=\frac{N_{o w}}{N_{w}}
$$


Besley (1999) gives the formulae for prediction of probability of overtopping in design and assessment manual of seawalls:

$$
P_{o w}^{\text {Besley }}=\left\{\begin{array}{lll}
55.41 Q_{*}^{0.634} & \text { for } \quad 0<Q_{*}<0.008 \\
2.502 Q_{*}^{0.199} & \text { for } \quad 0.008 \leq Q_{*}<0.01 \\
1 & \text { for } \quad Q_{*} \geq 0.01
\end{array}\right.
$$

where $Q_{*}[-]$ is the dimensionless average overtopping discharge:

$$
Q_{*}=\frac{q_{w}}{T_{m} g H_{s}}
$$

where $q_{w}$ is the average overtopping discharge, $T_{m}$ is the mean wave period of incoming wave, $H_{s}$ is the significant wave height of incoming wave.

Nørgaard et al. (2014) conducted a series of two-dimensional physical model tests on typical rubble mound breakwater geometries and provided a modification of Besley (1999) formula, to get better estimations in shallow water wave conditions. Based on the distribution of incident waves, they obtained a better prediction of probability of wave overtopping under shallow water condition:

$$
P_{o w}=P_{o w}^{\text {Besley }} \cdot C 1
$$


with

$$
C 1=\left\{\begin{array}{lll}
1 & \text { for } H_{m 0} / H_{1 / 10} \leq 0.848 \text { or } H_{m 0} / h \leq 0.2 \\
-6.65+9.02 \cdot \frac{H_{m 0}}{H_{1 / 10}} & \text { for } H_{m 0} / H_{1 / 10}>0.848 \text { and } H_{m 0} / h>0.2
\end{array}\right.
$$

where $H_{m 0}$ is the energy-based significant wave height, $H_{1 / 10}$ is the characteristic wave height, $h$ is the water depth.

In the EurOtop Manual (Pullen et al., 2007), another equation for prediction of probability of overtopping is given based on the run-up height by

$$
P_{o w}=\exp \left[-\left(\sqrt{-\ln 0.02} \frac{R_{c}}{R_{u 2 \%}}\right)^{2}\right\rfloor
$$

where $R_{c}$ is the freeboard and $R_{u 2} \%$ is the $2 \%$ run-up height (where run-up height is the vertical run-up elevation above still water level).

Franco et al. (1994) and Van der Meer and Janssen (1994) used the Weibull distribution with a shape factor of 0.75 and a scale factor $a$, which is dependent of the average overtopping discharge per wave and the overtopping probability, to represent the distribution of water volume in individual overtopping waves under positive freeboard condition $\left(R_{c}>0\right)$. The probability distribution function is given by 
$P_{V}=P\left(V_{i} \leq V\right)=1-\exp \left[\left(-\frac{V}{a}\right)^{b}\right]$

with

$$
a=0.84 \frac{T_{m} q_{w}}{P_{o w}}
$$

where $P_{V}$ is the probability of the overtopping volume per wave $V_{i}$ being less than or equal to $V$, and $b=0.75$ is the shape factor.

Victor et al. (2012) performed a detailed experimental study on the values of $b$ to improve the knowledge on the probability distribution of individual wave overtopping volumes on steep $(0.36$ $<\cot \alpha<1.69$, where $\alpha$ is the slope angle), low-crested $\left(0.10<R_{c} / H_{m 0}<1.69\right)$ smooth impermeable structures, and the study is also conducted under positive freeboard $\left(R_{c}>0\right)$. The effects of non-Rayleigh-distributed incident waves, slope angle, relative freeboard, and wave steepness were discussed. The prediction formula is given by

$$
b_{\text {Victor }}=\exp \left(-2.0 \frac{R_{c}}{H_{m 0}}\right)+(0.56+0.15 \cot \alpha)
$$

According to Pullen et al. (2007), $b$ is likely to increase in shallow-water wave conditions. Nørgaard et al. (2014) provided a modification of Eq. (9) to obtain a better prediction of $b$ under 
shallow water condition:

$b=b_{\text {Victor }} \cdot C 2$

with

$C 2=\left\{\begin{array}{lll}1 & \text { for } H_{m 0} / H_{1 / 10} \leq 0.848 \text { or } H_{m 0} / h \leq 0.2 \\ -10.8+13.9 \cdot \frac{H_{m 0}}{H_{1 / 10}} & \text { for } \quad H_{m 0} / H_{1 / 10}>0.848 \text { and } H_{m 0} / h>0.2\end{array}\right.$

Relatively, less is known about the wave overtopping under negative freeboard $\left(R_{c}<0\right)$. This case was referred to as "combined wave and surge overtopping" by Hughes and Nadal (2009). Under negative freeboard, in a large range of relative freeboard, the average overtopping discharge $q_{w s}$ is close to the steady overflow discharge without wave $q_{s}$ under the same freeboard, however, the peak instantaneous discharge can be several times the average discharge.

Wave overtopping discharge rate is a critical parameter in conceptual and preliminary design of levees. Based on physical experiments and numerical models, empirical formulae have been given by researchers to predict overtopping of levees under given wave conditions, water levels, and lining conditions (Hughes and Nadal, 2009; Li et al., 2012; Pan et al., 2013a; Pullen et al., 2007; Reeve et al., 2008; Yuan et al., 2014ab). One of the significant characteristics of wave overtopping under negative freeboard is that some of the overtopping parameters, e.g., average overtopping discharge and average flow velocity on landward-side slope, show different 
behaviors in different ranges of the relative freeboard $R_{d} / H_{m 0}$ (e.g., $R_{d} / H_{m 0}<-0.3$ and $-0.3 \leq$ $\left.R_{c} / H_{m 0}<0\right)$. Based on the result of a series of full-scale tests and the 25 -to- 1 test data of Hughes and Nadal (2009), Pan et al. (2013b) concluded that, in the range of $R_{d} / H_{m 0}<-0.3$, the combined wave and surge overtopping is surge-dominated and close to steady overflow, while in the range of $-0.3 \leq R_{d} / H_{m 0}<0$, the combined wave and surge overtopping is wave-dominated and close to wave overtopping under positive freeboard. As shown in Fig. 2, the rate $q_{w s} / q_{s}$ is close to 1 when $R_{d} / H_{m 0}<-0.3$; while it increases sharply with $R_{d} / H_{m 0}$ in the range of $-0.3 \leq R_{d} / H_{m 0}<0$. The $q_{w s}$ is accounted for combined overtopping discharge, and the $q_{s}$ is accounted for surge only overflow.

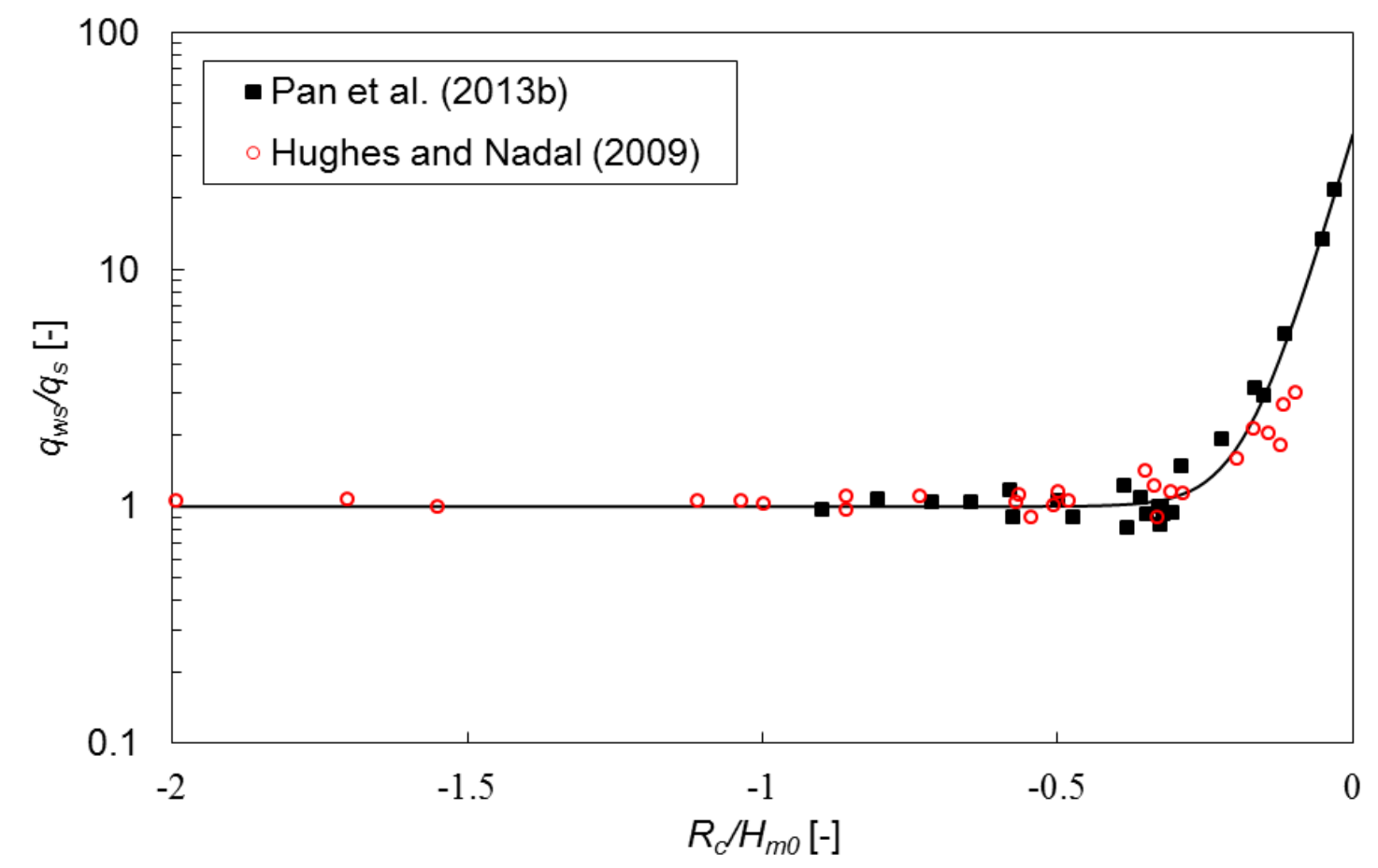

Fig. 2. Ratio of average overtopping discharge to the steady overflow discharge $\left(q_{w s} / q_{s}\right)$ versus relative freeboard $\left(R_{d} / H_{m 0}\right)$. 
The general relationship between $q_{w s}$ and $q_{s}$ for levees with both impermeable and permeable lining, as shown by the solid line in Fig. 2, is given by Pan et al. (2013b):

$$
q_{w s} / q_{s}=36.12 \exp \left(19.59 \frac{R_{c}}{H_{m 0}}\right)+1
$$

where $q_{s}$ can be calculated by the well-known equation of open channel flow (Kindsvater, 1964):

$$
q_{s}=C_{f} \sqrt{g} h_{1}^{3 / 2}
$$

where $h_{l}$ is the upstream head $\left(h_{l}=-R_{c}\right)$ and $C_{f}$ is empirical coefficient. For impermeable levees, e.g., levee with RCC lining, the $C_{f}$ can be taken as 0.5445 (Henderson, 1966; Hughes and Nadal, 2009; Pan et al., 2013b); for levees protected by permeable linings on crest and landward-side slope, $C_{f}$ can be determined by experiments, e.g., 0.444 for ACB and 0.415 for HPTRM (Pan et al., 2013b).

Based on the results of a series of 25-to-1 laboratory tests with negative freeboard, Hughes and Nadal (2009) developed equations for the distribution of individual wave volumes of the water overtopping under negative freeboard. Two-parameter Weibull distribution, as shown by Eq. (7), was used to represent the distribution of individual wave volumes. The equations to predict the scale factor $a\left[\mathrm{~m}^{3} / \mathrm{m}\right]$ and the shape factor $b[-]$ are given by 


$$
a=0.79 q_{w s} T_{p}
$$

$$
b=15.7\left(\frac{q_{s}}{g T_{p} H_{m 0}}\right)^{0.35}-2.3\left(\frac{q_{s}}{\sqrt{g H_{m 0}^{3}}}\right)^{0.79}
$$

where $T_{p}$ is the peak wave period.

Hughes et al. (2012) proposed another equation to estimate the Weibull shape factor $b$ with relative freeboard $R_{C} / H_{m 0}$, using the data of Van der Meer and Janssen (1995), Hughes and Nadal (2009) and Victor et al. (2012). The equation is given as

$$
b=\left(\exp \left(-0.6 \frac{R_{c}}{H_{m 0}}\right)\right)^{1.8}+0.64
$$

Eq. (16) represents the general distribution of Weibull shape factor $b$ in a large range of relative freeboard $\left(-1.5 \leq R_{C} / H_{m 0}<4.0\right)$ well, and it does not depend on the seaward slope angle. However, as mentioned in Hughes et al. (2012), in a specific condition (e.g., steep slopes), the performance of the equation derived from test data in similar condition would be better.

Since the probability of overtopping is 1 , the overtopping discharge under negative freeboard is almost continuous except for some breaks between two large waves. Thus, the instantaneous overtopping discharge could also be represented by Weibull distribution. Hughes and Nadal (2009) provided Eqs. (17) and (18) for scale factor $a_{i n}\left[\mathrm{~m}^{3} / \mathrm{s} / \mathrm{m}\right]$ and the shape factor $b_{\text {in }}[-]$ based on the laboratory tests. 


$$
\begin{aligned}
& a_{i n}=\frac{q_{w s}}{\Gamma\left(1+\frac{1}{b_{i n}}\right)} \\
& b_{i n}=8.10\left(\frac{q_{s}}{g T_{p} H_{m 0}}\right)^{0.34}
\end{aligned}
$$

\section{Description of laboratory experiments}

The model tests used for the present analysis are described in Li et al. (2012) and Pan et al. (2013a). The full-scale tests were conducted in the Large Wave Flume (LWF) of the O.H. Hinsdale Wave Research Laboratory (HWRL) at Oregon State University. A definition sketch of the test set-up is shown in Fig. 3. The LWF is a $104 \mathrm{~m} \times 3.66 \mathrm{~m} \times 4.57 \mathrm{~m}$ (length $\times$ width $\times$ height) flume equipped with a unidirectional piston wave maker. The levee model was built with a sand core and a concrete cap with a $0.76 \mathrm{~m}$ deep test section in which the tested linings, RCC, ACB and HPTRM are installed.

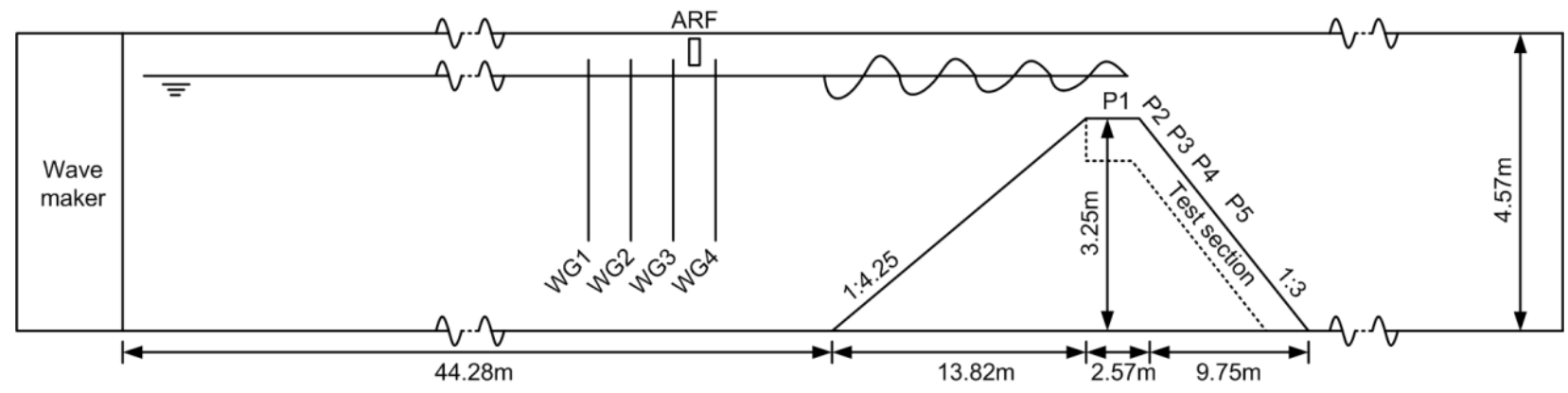

Fig. 3. Illustration of the LWF and the test set-up. 
Four surface-piercing wave gauges (Imtech Inc.), WG 1 to WG4, were placed near the seaward-side toe of the levee. The Acoustic Range Finder (Senix TS-30S1), ARF, placed between WG 3 and WG 4 was used to calibrate the wave gauges. The flow depths and flow velocities at P1 to P5 along the crest and landward-side slope are recorded by Acoustic Range Finders (ARF) and Acoustic Doppler Velocimeters (ADV), respectively. At each point one ARF sensor and two ADV sensors at different levels are installed. A pump system was used to provide return flow to counterbalance the mean overtopping due to waves.

Irregular wave time series realization was generated conforming to the idealized TMA (Texel-Marsen-Arsloe) wave spectrum. A total of 24 different conditions were designed, with 17 cases in the range of $R_{d} / H_{m 0}<-0.3$ and 7 cases in the range of $-0.3 \leq R_{d} / H_{m 0}<0$. The test ranges in this paper are listed in Table 1. In the 24 cases, different strengthening systems are tested in the test section, including 11 cases for RCC, 4 cases for ACB, and 9 cases for HPTRM. However, the strengthening systems mainly influence the apparent overtopping discharge and the flow condition on the landward-side slope and only have slight effect on the distribution of the overtopping volume. Hence, in this paper, the effects of the strengthening systems are not discussed.

\section{Wave parameters, overtopping discharges and individual overtopping volumes}

The incident wave parameters and overtopping discharges were calculated using MatLab ${ }^{\circledR}$ 
scripts based on the measurements of the wave gauges, ARF sensors and ADV sensors.

The incident and reflected waves are separated using the measurements of WG1 to WG4 with a least squares method of Mansard and Funke (1980), and then the wave spectrum of the incident wave is derived from the time series of incident wave using a fast Fourier transform (FFT) algorithm. The significant wave height $H_{s}$ and mean wave period $T_{m}$ are obtained from the time series of the incident wave, and the energy-based significant wave height $H_{m 0}$, peak wave period $T_{p}$ and mean (energy) wave period $T_{m-1,0}$ are calculated from the incident wave spectrums.

The time series of flow depth and time series of flow velocity (from 2 ADV sensors at different levels) at P1 in the middle of the levee crest were used to estimate the time series of overtopping discharge, and averages were calculated for all data points to obtain the overtopping discharge $q_{w s}$ for all 24 experiments. Another characteristic overtopping discharge used in this study is the steady overflow discharge $q_{s}$. For all the cases the values of steady overflow discharge $q_{s}$ were calculated under the same freeboard with Eq. (13).

Individual waves for each experiment were identified from the time series of flow depth measured at P1. Using the starting and ending time step for each identified wave, the wave volume $V$ was calculated by integrating the corresponding region of the calculated instantaneous overtopping discharge time series at P1 over those same time steps.

\section{Table 1}

Test ranges of the full-scale flume tests (Pan et al., 2013b).

\begin{tabular}{ccccccc}
\hline Parameter & $R_{c} / H_{m 0}[-]$ & $H_{m 0} / h[-]$ & $R_{c}[\mathrm{~m}]$ & $H_{m 0}[\mathrm{~m}]$ & $T_{p}[\mathrm{~s}]$ & $q_{w s}\left[\mathrm{~m}^{3} / \mathrm{s} / \mathrm{m}\right]$ \\
Tested ranges & $-0.833 \sim-0.036$ & $0.104 \sim 0.213$ & $-0.343 \sim-0.017$ & $0.37 \sim 0.74$ & $3.36 \sim 7.07$ & $0.083 \sim 0.339$ \\
\hline
\end{tabular}




\section{Distribution of incident waves}

The distribution of incident waves can influence the value of the shape factor $b$ of the Weibull distribution of the individual overtopping volumes. According to the observation of Victor et al. (2012), under positive freeboard, tests with non-Rayleigh incident waves correspond to larger values of the shape factor $b$. Three examples of measured incident wave height distributions are shown in Fig. 4. Fig. 4(a) is an example of well Rayleigh wave, which is measured in approximately $1 / 4$ of all the cases. Fig. 4(b) is an example of typical non-Rayleigh wave, similar to some cases of the measurement of Victor et al. (2012) and Nørgaard et al. (2014), showing a trend of less large waves than Rayleigh distribution. This type of distribution is measured in approximately $3 / 4$ of all the cases. Fig. 4(c) is an unreasonable distribution measured in ACB test 1, showing a trend of more large waves than Rayleigh distribution. The distribution of this case is different from all other cases and the reason might be an error in measurement. The unreasonable distribution is provided here to explain the obvious deviation of one data point in some of the figures, as shown in following sections. 

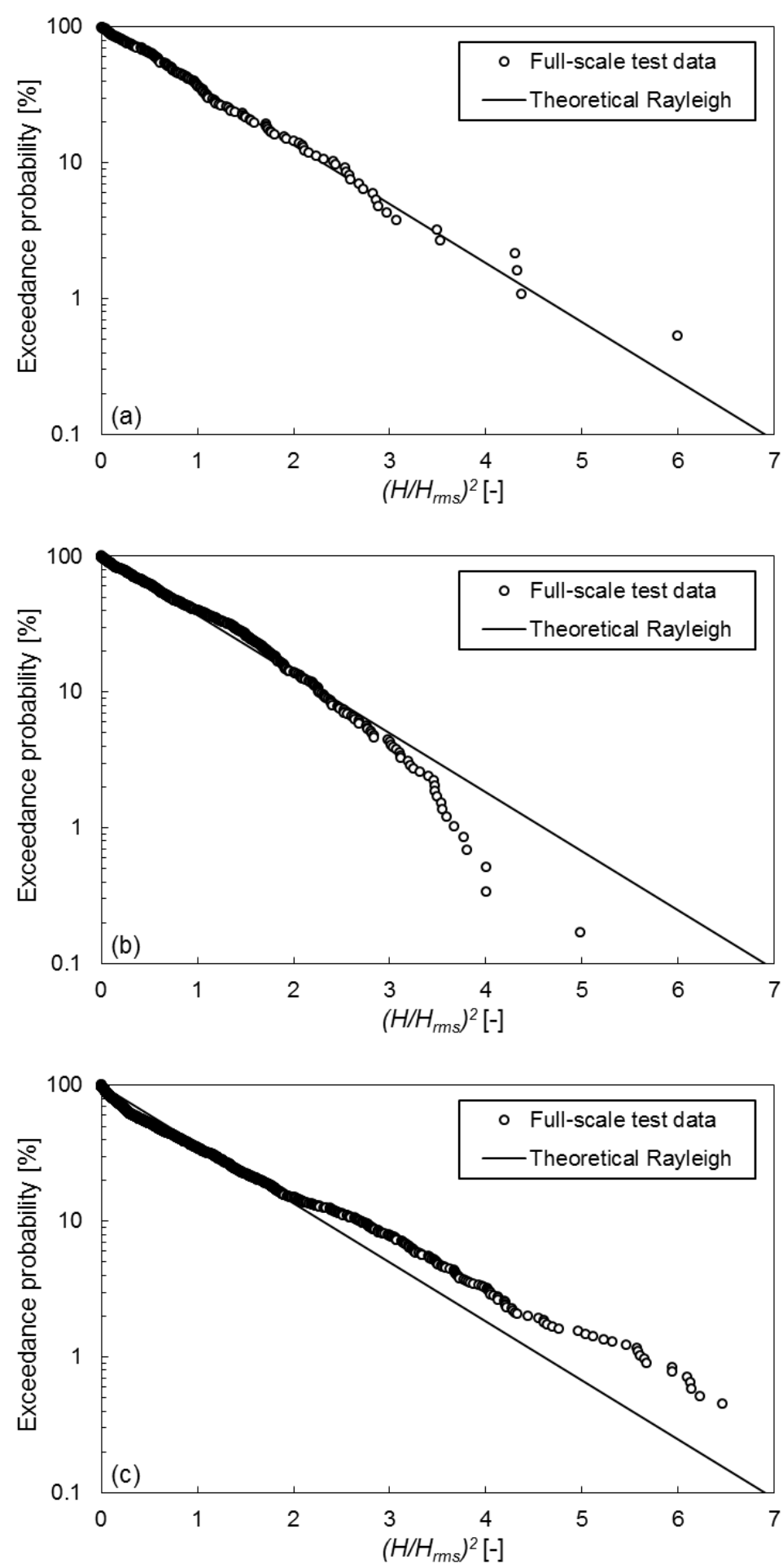

Fig. 4. Examples of exceedance probability distribution of incident wave height for the full-scale tests. (a) Example of the cases fit well with Rayleigh distribution from RCC test 6. (b) Example of the cases with non-Rayleigh distributed waves from HPTRM test 5. (c) The case with unreasonable distribution from ACB test 1. 


\section{Wave overtopping patterns}

Under negative freeboard, the overtopping discharge is almost continuous except for some breaks between two large waves, and the probability of overtopping is 1 . However, according to the observation during the tests, the waves pass the levee crest in four different patterns, which lead to different ways of energy dissipation and effects to the levee. The four passing patterns are illustrated in Fig. 5, and include plunging breakers on seaward-side slope (case 1), plunging breakers on crest (case 2), waves passing smoothly without breaker (case 3), and waves passing smoothly with spilling breakers (case 4). In cases 1 and 2, plunging breaker and a great deal of energy dissipation occurs, leading to more broken wave front and turbulent mix of water flow. Thus, in cases 1 and 2, the waves have more erosion effects on the crest. In cases 3 and 4, without fierce plunging breaker, the waves have less broken wave front and thus large wave front velocity occurs on landward-side slope. Hence in cases 3 and 4, the waves have more erosion effects on the landward-side slope. According to the characteristic of breaking, case 1 and case 2 can be summarized as breaking passing, and case 3 and case 4 can be summarized as smooth passing. 

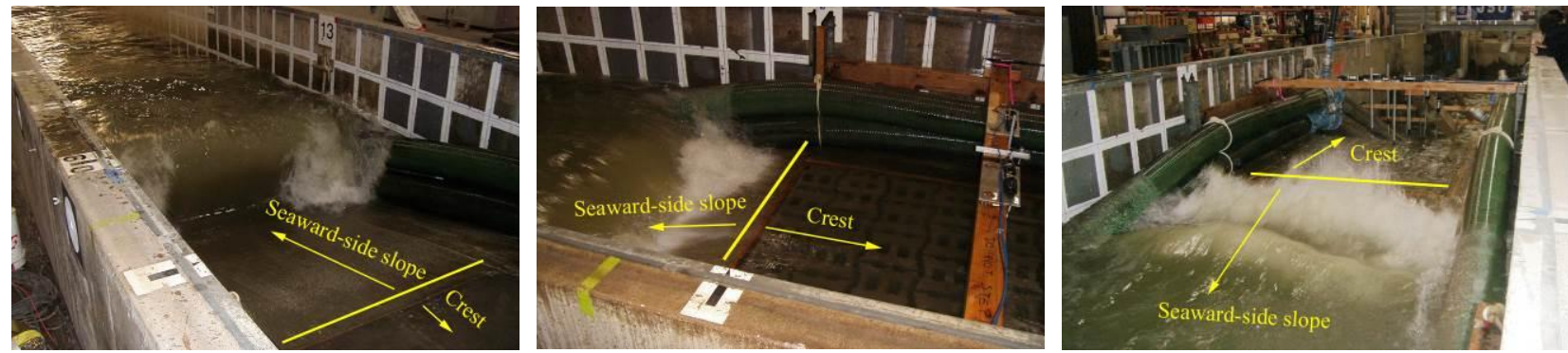

(a) plunging breakers on seaward-side slope
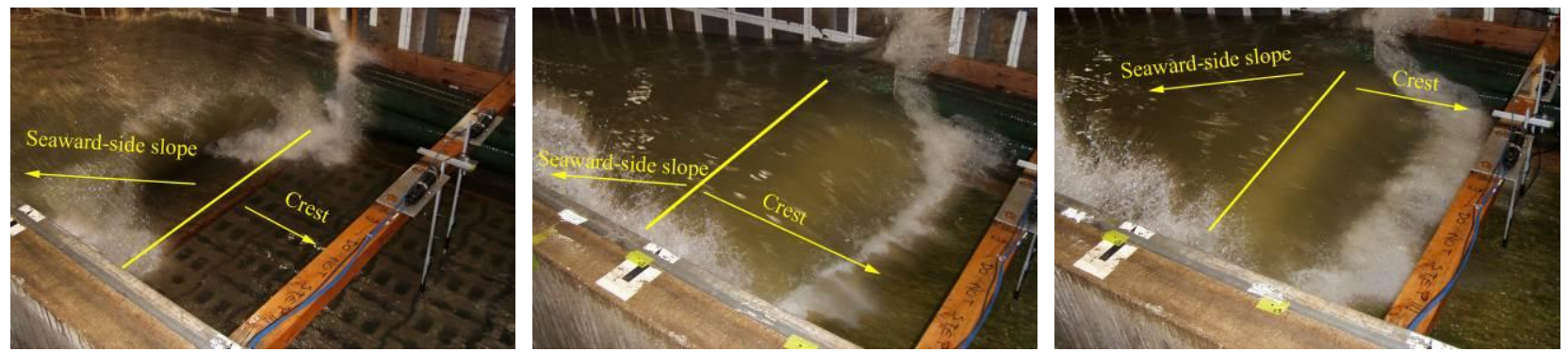

(b) plunging breakers on crest
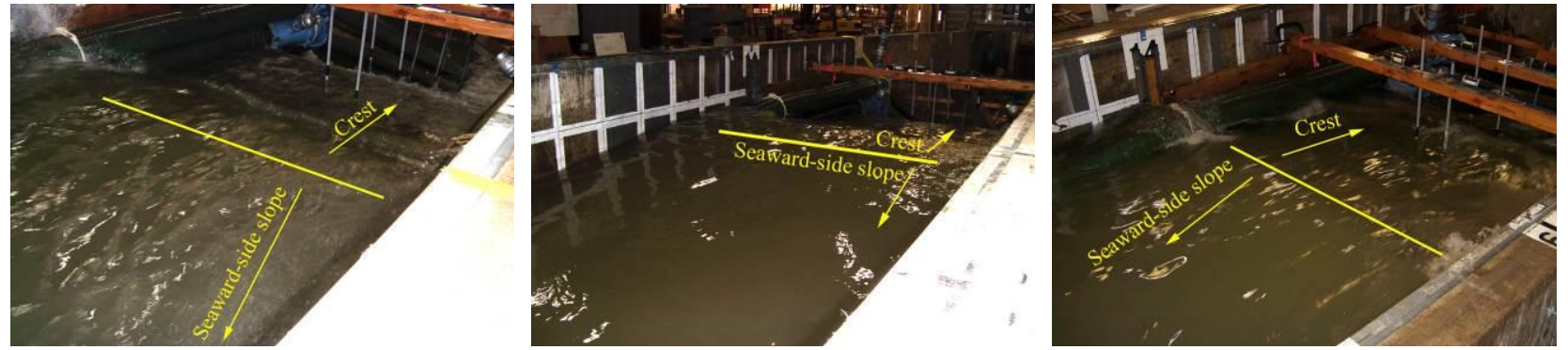

(c) waves passing smoothly without breaker
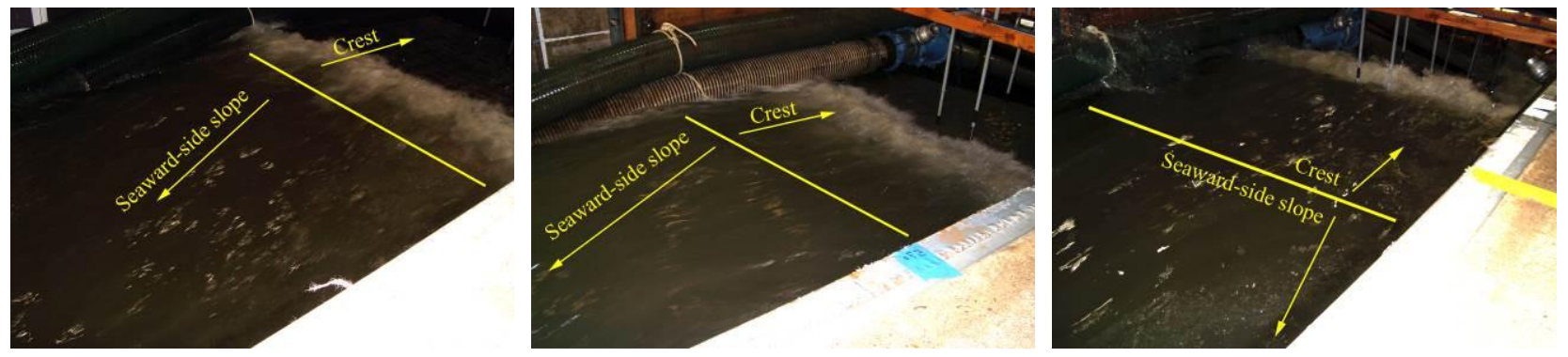

(d) waves passing smoothly with spilling breakers

Fig. 5. Wave overtopping patterns under negative freeboard: (a) case 1, plunging breakers on seaward-side slope; (b) case 2, plunging breakers on crest; (c) case 3, waves passing smoothly without breaker; (d) case 4, waves passing smoothly with spilling breakers.

The numbers of different wave passing patterns were recorded during the overtopping tests.

For each recorded test, the numbers of waves for the four cases of wave passing patterns were 
counted and probabilities of occurrence were calculated. The probabilities of occurrence of breaking passing and smooth passing versus relative freeboard $R_{d} / H_{m 0}$ are plotted in Fig. 6, which indicates that the breaking passing is more likely to occur with small absolute value of $R_{c} / H_{m 0}$, while smooth passing is more likely to occur with large absolute value of $R_{c} / H_{m 0}$. This can be explained by the physical meaning of relative freeboard $R_{d} / H_{m 0}$ under negative freeboard. Relative freeboard $R_{d} / H_{m 0}$ is the ratio of freeboard $R_{c}$ (negative) and the significant wave height based on energy spectrum $H_{m 0}$. It reflects the proportional relationship between wave overtopping and surge overflow in the combination of wave overtopping and steady overflow. A small absolute value of $R_{d} / H_{m 0}$ indicates that the wave overtopping is more dominant compared to the surge overflow, and hence breaking passing is more likely to occur. A large absolute value of $R_{d} / H_{m 0}$ indicates that the surge overflow is more dominant compared to the wave overtopping, and hence smooth passing is more likely to occur. 


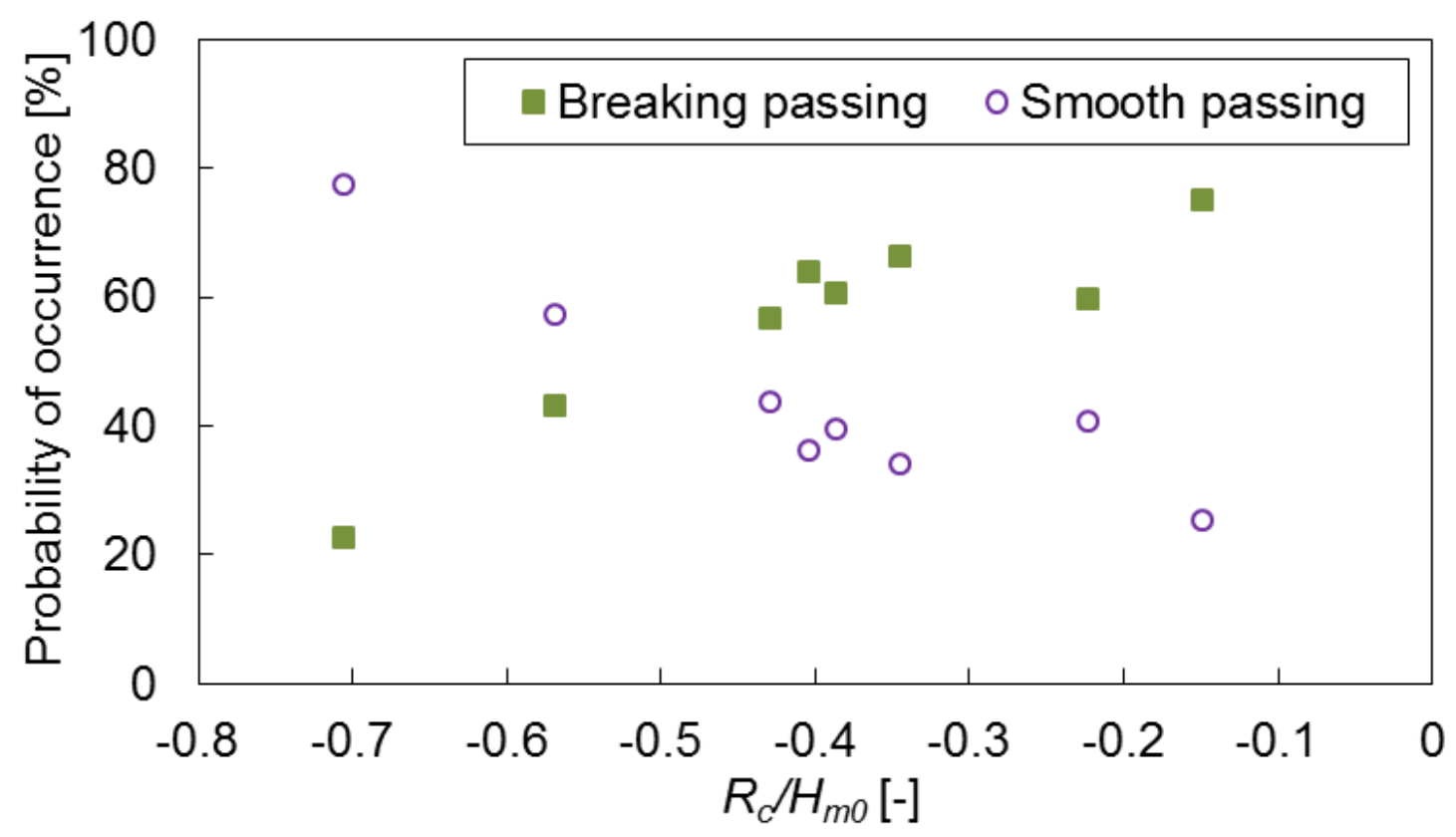

Fig. 6. Effect of relative freeboard on wave overtopping patterns.

In order to estimate the probabilities of occurrence of breaking passing and smooth passing, the recorded probabilities of occurrence versus dimensionless overtopping discharge $Q_{*}$ are plotted in Fig. 7. The $Q_{*}$ is given according to Eq. (3) with $q_{w}$ being replaced by $q_{w s}$. As seen in Fig. 7, the recorded probabilities give a nice trend with different $Q_{*}$, and the solid lines are best-fit curves given by Eq. (19)

$$
\begin{aligned}
& P_{s p}=100 \cdot \tanh \left(1788 Q_{*}^{1.66}\right), \\
& P_{b p}=100-P_{s p}
\end{aligned}
$$

where $P_{s p}[\%]$ is the probability of occurrence for smooth passing, and $P_{b p}[\%]$ is the probability of occurrence for breaking passing. The best-fit equation has an R-square (coefficient of 
determination) of 0.9877 and an RMSE (root-mean-square error) of 1.84 . However, it should be mentioned that Eq. (19) should be used with caution out of the tested range, especially in the range of small $Q_{*}$ when the behavior of wave overtopping discharge may be different as in the range of $-0.3 \leq R_{d} / H_{m 0}<0$ in Fig. 2.

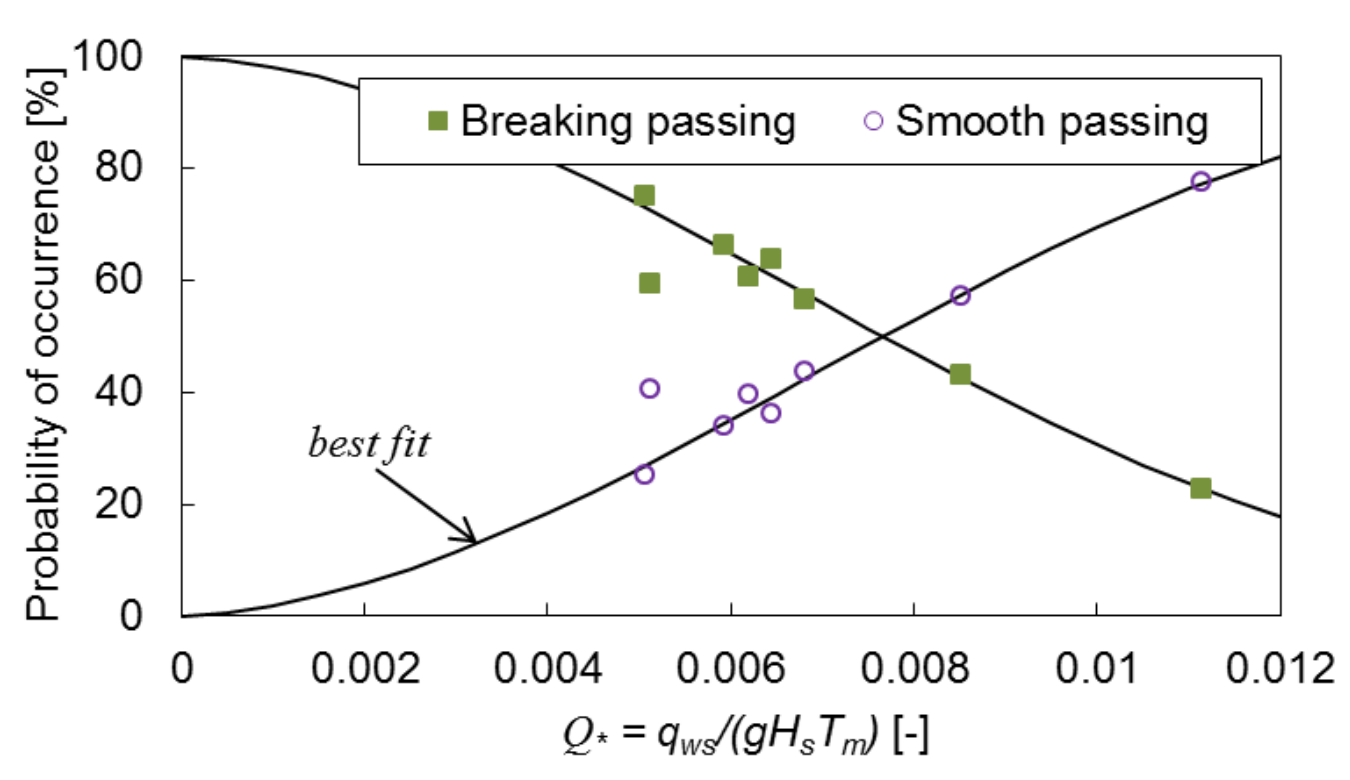

Fig. 7. Estimate of wave overtopping patterns.

\section{Distribution of individual overtopping volumes}

Two-parameter Weibull distribution, as shown by Eq. (7), was used to represent the distribution of individual wave volumes. Fig. 8 shows an example of a good fit (a) from RCC test 10 and a mediocre fit (b) from HPTRM test 5 of the Weibull distribution to individual wave overtopping volumes (given as percent exceedance distributions). Generally for all the cases, the 
fitting degrees between the test data and Weibull distribution are between the two cases shown in Fig. 8.

Because the results of the full-scale tests are mainly compared to the 25-to-1 laboratory test results of Hughes and Nadal (2009), in this paper the Weibull distribution is fitted to all the individual wave volumes, as in Hughes and Nadal (2009). However, it should be mentioned that in some other studies only large individual wave volumes were used to get a best fit, e.g., in Victor et al. (2012) only the individual volumes that larger than the average wave volume $V_{\text {mean }}$ were used, and in Hughes et al. (2012) only the upper $10 \%$ of the wave volumes were used. The best fit with all the wave volumes, as in this paper, would perform better in representing the main part of the distribution of individual volumes, and less better in representing the largest individual volumes. If the fitting the Weibull distribution is good, as shown in Fig. 8(a), the using of all the individual volumes would have little influence on representing the largest individual volumes. As shown in Fig. 11 and discussed later, the estimation of the mean individual volume is good and the estimation of the maximum individual volume is mediocre but in good trend. 

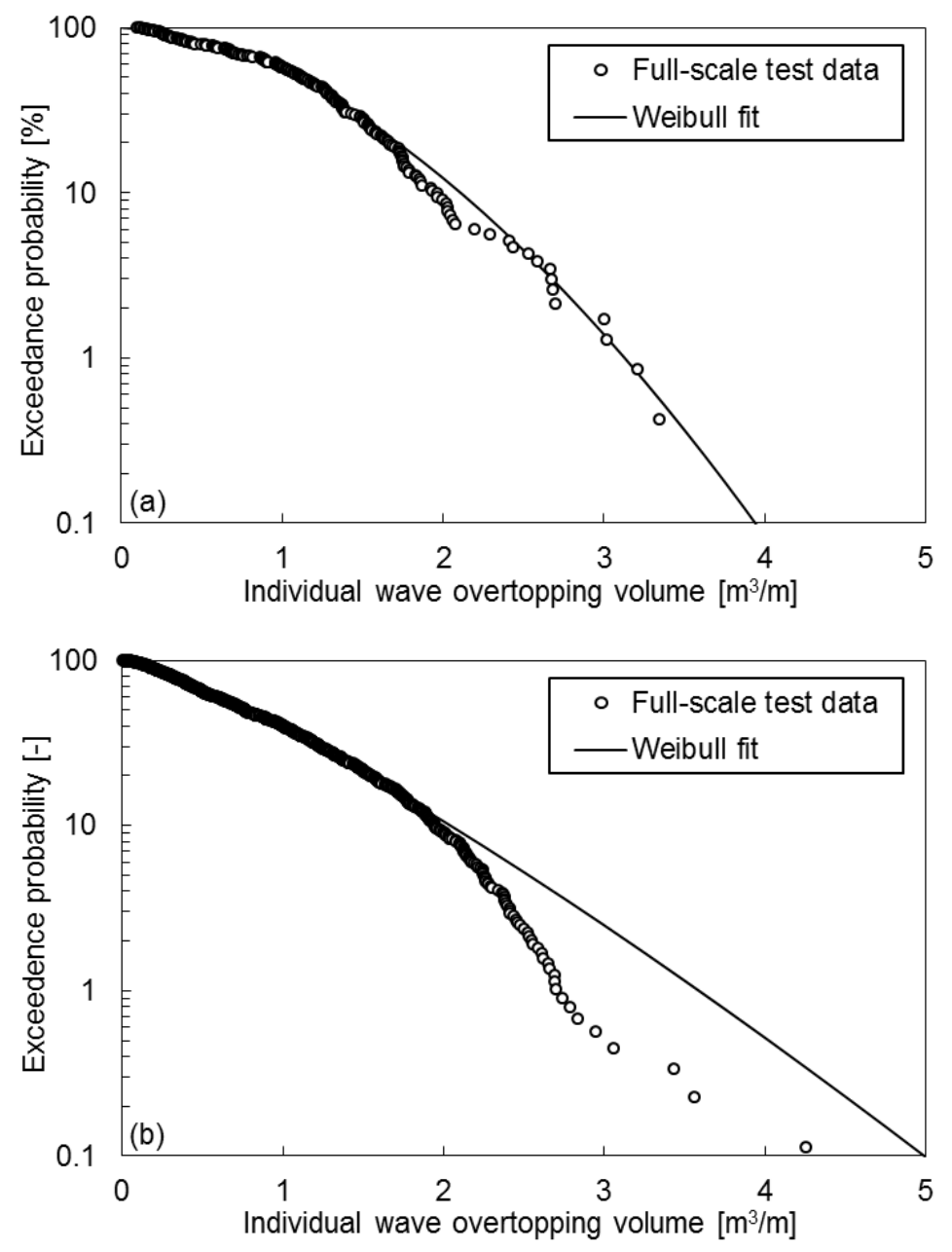

Fig. 8. Example of best fits of Weibull distribution to individual wave overtopping volume. (a) Example of a good fit from RCC test 10. (b) Example of a mediocre fit from HPTRM test 5.

In Fig. 9, the fitted shape factor $b$ of Weibull distribution is plotted versus dimensionless overtopping discharge $q_{w s} /\left(g H_{m 0} T_{p}\right)$. As shown in Fig. 2, some of the overtopping parameters show different behaviors in different ranges of the relative freeboard $R_{c} / H_{m 0}$ divided by $R_{c} / H_{m 0}=$ -0.3. Hence, in Fig. 9, different symbols are used in different range of $R_{c} / H_{m 0}$. Nice trends in fitted $b$ with increasing dimensionless discharge could be found in the range of $R_{C} / H_{m 0}<-0.3$ and $-0.3 \leq R_{d} / H_{m 0}<0$ separately. The solid lines in Fig. 9 are the best fit curves given by the formulae 


$$
\begin{aligned}
& b=73.55\left(\frac{q_{w s}}{g H_{m 0} T_{p}}\right)^{0.76} \quad \text { for } \quad R_{c} / H_{m 0} \leq-0.3 \\
& b=54.58\left(\frac{q_{w s}}{g H_{m 0} T_{p}}\right)^{0.63} \quad \text { for }-0.3<R_{c} / H_{m 0}<0
\end{aligned}
$$

The best-fit equation for $R_{c} / H_{m 0}<-0.3$ has an R-square of 0.9749 and an RMSE of 0.1438 , and the best-fit equation for $0.3 \leq R_{c} / H_{m 0}<0$ has an R-square of 0.8526 and an RMSE of 0.2065. Significant deviation can be found for one data point $(0.0063,2.43)$ in the range of $R_{C} / H_{m 0}<-0.3$. This may be explained by the fact that in ACB test 1, unreasonable distribution of incident wave was recorded, as shown in Fig. 4(c). There might be a wrong measurement in this case, and hence this data point is only plotted here but not used for the purpose of fitting.

The estimates of Hughes and Nadal (2009) using Eq. (15) are also plotted in Fig. 9. As shown in Fig. 9, the estimates of Hughes and Nadal (2009) derived from 25-to-1 laboratory tests has the same distribution trend of the fitted $b$ in the full-scale tests. This confirms the validity of Eq. (20). However, the distinction between different ranges of $R_{c} / H_{m 0}$ in Eq. (20) gives better estimates of $b$, especially for the low discharge cases, in which the two distributions trends are distinguished clearly. 


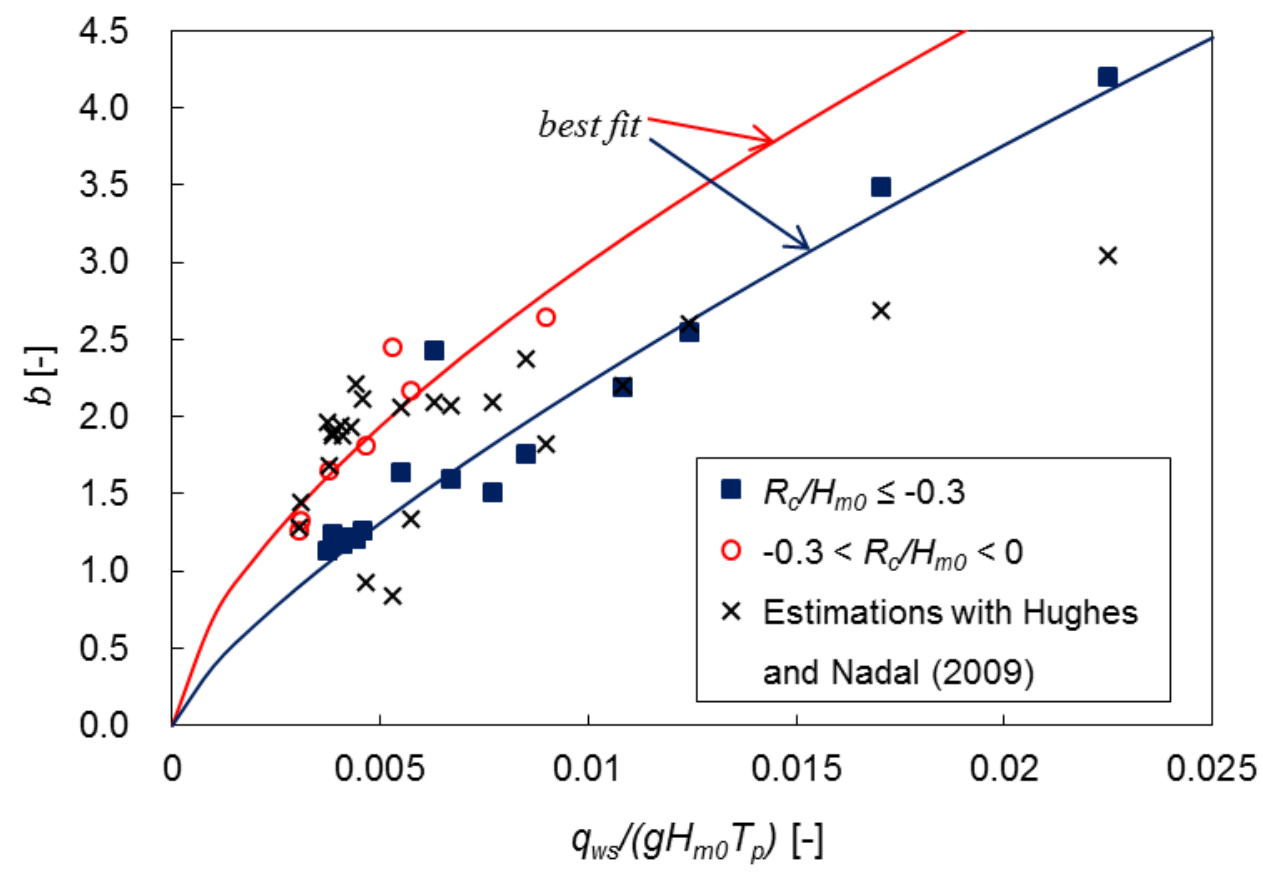

Fig. 9. Best fit equations for Weibull factor $b$.

Based on Eqs. (8) and (14), the scale factor $a$ of Weibull distribution has a linear relationship with the product of the overtopping discharge and the characteristic wave period of the incident wave. In this study, the peak period $T_{p}$, the mean period $T_{m}$ and the mean (energy) wave period $T_{m-1,0}$ were examined as the characteristic wave periods. After several attempts, mean (energy) wave period $T_{m-1,0}$ was proved to be slightly better than the peak period $T_{p}$ and the mean period $T_{m}$ to fit well with $a$. In Fig. 10, the fitted scale factor $a$ is plotted versus overtopping parameter $q_{w s} T_{m-1,0}$. In the range of $R_{c} / H_{m 0}<-0.3$ and $-0.3 \leq R_{c} / H_{m 0}<0$, the same trend for $a$ could be found with an increase in $q_{w s} T_{m-1,0}$. The crosses in Fig. 10 are the estimations with the equation of Hughes and Nadal (2009) given in Eq. (14). It can be seen that Eq. (14) fits relatively well with the data of full-scale test, with slight underestimations. One possible explanation of the slight 
deviation between the results of full-scale test and Hughes and Nadal (2009) is the model and measurement effects, resulting from different modelling techniques and measurement equipment. According to the EurOtop manual (Pullen et al., 2007), the wave overtopping parameters between two wave flumes could have a $\mathrm{CoV}$ (coefficient of variation) up to $13 \%$ due to model and measurement effects. The best fit of the data is given by the solid line in Fig. 10 and Eq. (21), and due to limited data points, Eq. (21) is only given tentatively and needs future validation. The Eq. (21) has an R-square of 0.8061 and an RMSE of 0.1654. The two data points in Fig. 10 with values of $q_{w s} T_{m-1,0}$ greater than 2 deviated significantly from the data trend. The two points came from RCC test 7 and 9. A possible explanation for the observed deviation might be the presence of relatively large $T_{p}(6.97 \mathrm{~s}$ and $7.04 \mathrm{~s}$ in the range of $3.36 \sim 7.07 \mathrm{~s}$ for all the tests, as listed in Table 1). The other points with large $T_{p}$ also tend to be lower than the average trend, but not so significant. However, the number of data points is not sufficient to draw a conclusion, and this explanation needs more data for validation.

$a=1.017 q_{w s} T_{m-1,0}$ 


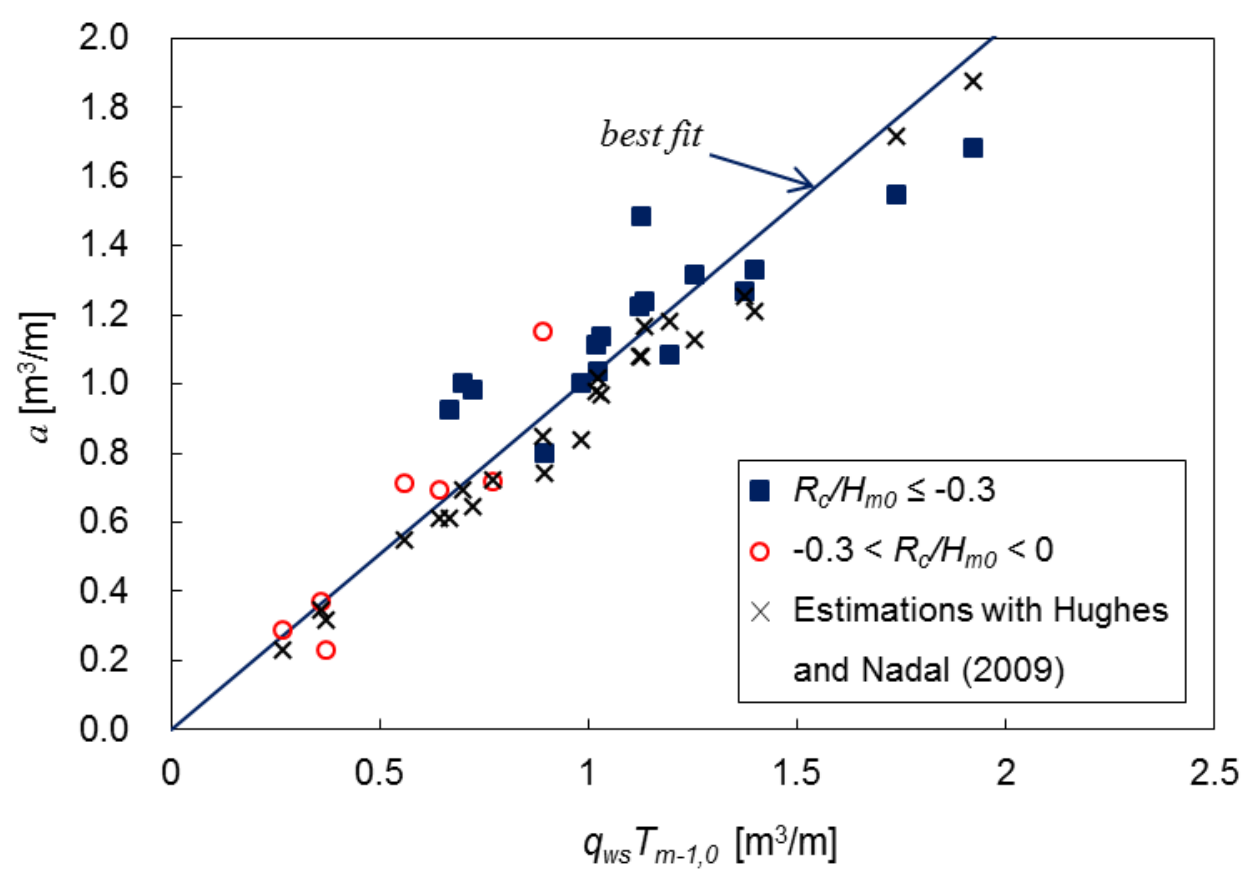

Fig. 10. Best fit equation for Weibull factor $a$.

The mean and maximum value of the Weibull distribution can be calculated in terms of the values of scale factor $a$ and shape factor $b$ as (e.g., Victor et al., 2012; Nørgaard et al., 2014)

$V_{\text {mean }}=a \cdot \Gamma\left(1+\frac{1}{b}\right)$

and

$V_{\max }=a \cdot(\ln (N+1))^{1 / b}$

where $\Gamma$ is the gamma function and $N$ is the overtopping wave number. From Eqs. (20) and (21), 
the scale factor $a$ and shape factor $b$ were calculated for all experiments, and then Eqs. (22) and (23) were used to estimate the mean and maximum individual overtopping volumes based on the calculations of $a$ and $b$. Comparisons between estimated and measured values for mean and maximum individual overtopping volumes are shown in Fig. 11(a) and 11(b), respectively. A better prediction can be found for mean individual overtopping volumes, except for the overestimation of two data points due to overestimated values of $a$, as shown in Fig. 10. The estimation of maximum individual overtopping volumes is mediocre but reasonable. The data trend is good but the data points are scattered because of limited wave numbers and the randomness of the maximum value in limited cases.

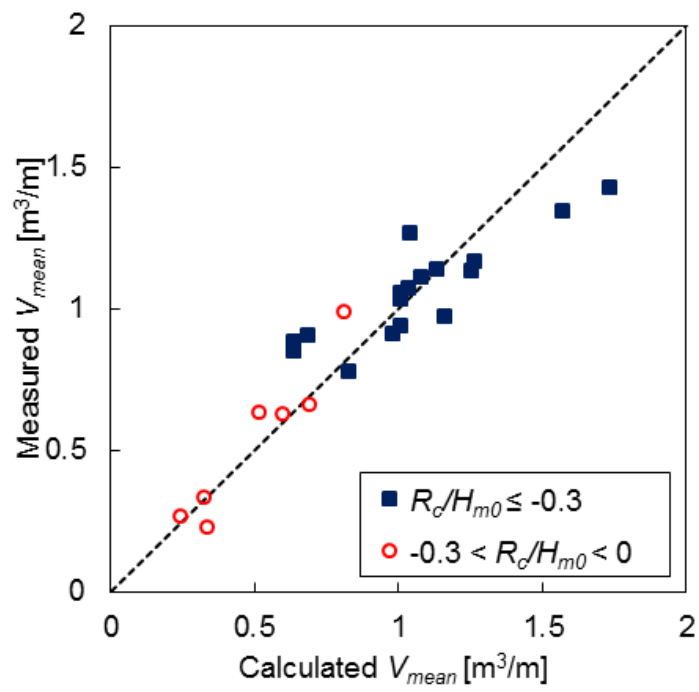

(a) Mean individual volume

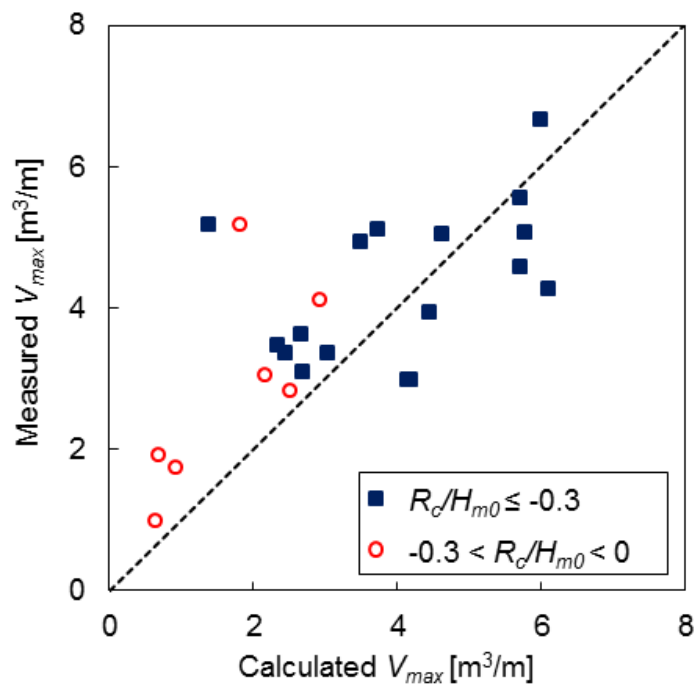

(b) Maximum individual volume

Fig. 11. Comparison of measured and calculated characteristic overtopping volumes.

\section{Distribution of instantaneous overtopping discharge}


In addition to the individual wave overtopping volumes, the instantaneous overtopping discharge is also an important factor in the design and protection of levees, because the peak discharge can be several times the mean discharge and in many cases is the reason for levee failure. In this paper, two-parameter Weibull distribution, as shown by Eq. (7), was used to represent the distribution of instantaneous overtopping discharge, with the Weibull factors $b_{\text {in }}$ and $a_{i n}$ for instantaneous overtopping discharge replacing the Weibull factors $b$ and $a$ for individual wave overtopping volumes. Fig. 12 shows an example of a good fit (a) from RCC test 5 and a mediocre fit (b) from RCC test 10 of the Weibull distribution to instantaneous overtopping discharge (given as percent exceedance distributions). Generally for all the cases, the fitting degrees between the test data and Weibull distribution are between the two cases shown by Fig.

12.

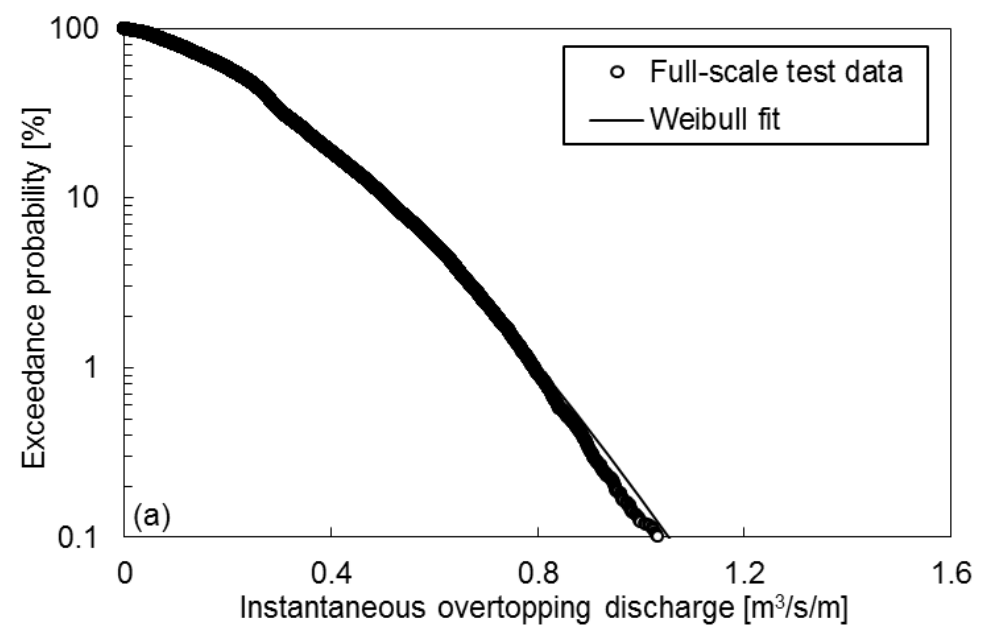




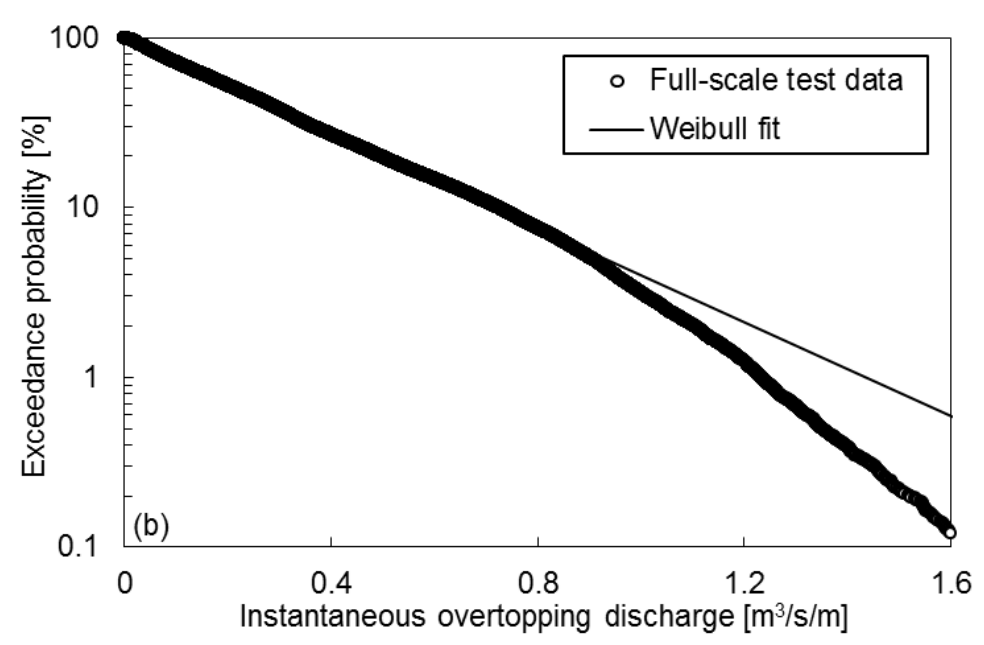

Fig. 12. Example of best fits of Weibull distribution to instantaneous overtopping discharge. (a) Example of a good fit from RCC test 5. (b) Example of a mediocre fit from RCC test 10.

The fitted shape factor $b_{\text {in }}$ of Weibull distribution is plotted versus dimensionless overtopping discharge $q_{s} /\left(g H_{m 0} T_{p}\right)$ in Fig. 13. The $q_{s}$ is the steady overflow discharge under the same freeboard calculated by Eq. (13). It should be noted that the parameter $q_{s} /\left(g H_{m 0} T_{p}\right)$ used here is different from the parameter $q_{w s} /\left(g H_{m 0} T_{p}\right)$ used in Fig. 9. The data points are also compared to the equation (Eq. (18)) and measurements of Hughes and Nadal (2009) derived from 25-to-1 laboratory tests. As shown in last section, the fitted Weibull factors $b$ and $a$ for individual wave overtopping volumes from the full-scale test are quite close to the estimations of Hughes and Nadal (2009), at least in the same distribution trend. However, the distribution of the Weibull factors $b_{\text {in }}$ for instantaneous overtopping discharge from the full-scale tests has an obvious deviation from the estimation of Hughes and Nadal (2009), as seen from Fig. 13. The values of $b_{\text {in }}$ from full-scale tests are obviously smaller than the estimation of Hughes and Nadal (2009), implying that the full-scale tests have more large values of instantaneous overtopping discharge, according to the characteristics of Weibull distribution (e.g., Pan et al., 2013b). One possible 
explanation of the deviation between the results of full-scale test and Hughes and Nadal (2009) is the model and measurement effects, resulting from different modelling techniques and measurement equipment, e.g., in full-scale tests, the ARF sensors might be measuring the depth of aerated flow induced by plunging breakers and that would give a higher instantaneous discharge than actual. The best fit of the data is given by the solid line in Fig.13 and Eq. (24).

$b_{i n}=30.64 \cdot q_{s} /\left(g H_{m 0} T_{p}\right)+0.8$

The best-fit equation has an R-square of 0.5497 and an RMSE of 0.1242 . When parameter $q_{s} /\left(g H_{m 0} T_{p}\right)$ equals to 0 , it is wave overtopping under zero freeboard condition (as shown in Fig. 1(b)) and the $b_{\text {in }}\left(q_{s} /\left(g H_{m 0} T_{p}\right)=0\right)$ is the shape factor of the Weibull distribution of instantaneous overtopping discharge under zero freeboard condition. It is considered that, the distribution of instantaneous overtopping discharge under zero freeboard should be similar to that under very small negative freeboard, so the y-intercept of the best fit curve of $b_{\text {in }}$ should be close to the value of $b_{\text {in }}$ with very small value of $q_{s} /\left(g H_{m 0} T_{p}\right)$. Hence, it is reasonable to apply a linear relationship to represent the $b_{\text {in }}$ in this study. The $b_{i n}=0.8\left(q_{s} /\left(g H_{m 0} T_{p}\right)=0\right)$ is a best-fit value and it also can be confirmed by the measurements by Hughes and Nadal (2009); as seen in Fig. 13 , when parameter $q_{s} /\left(g H_{m 0} T_{p}\right)$ is very small, the values of fitted $b_{i n}$ are around 0.8 , both in the full scale tests and the laboratory tests of Hughes and Nadal (2009). 


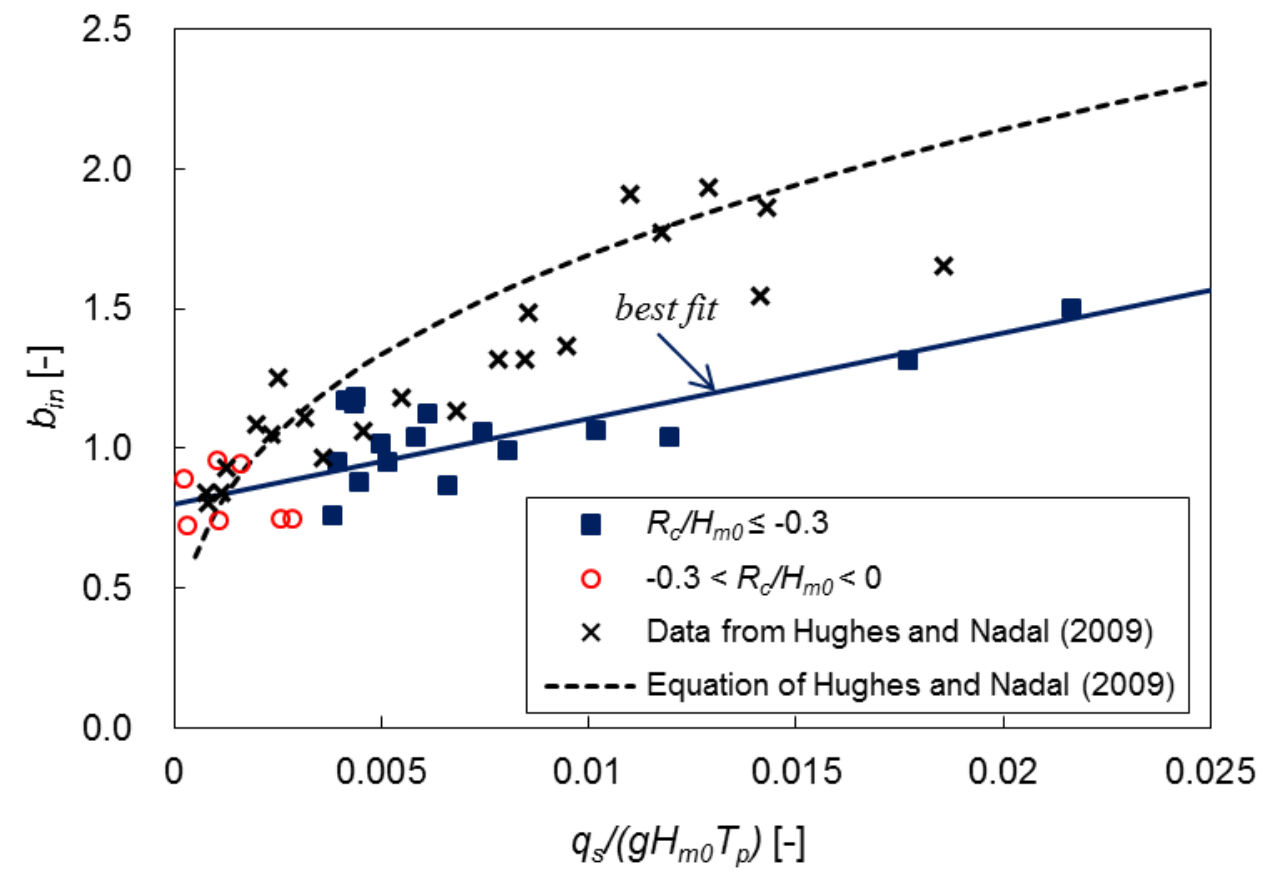

Fig. 13. Best fit equation for Weibull factor $b_{i n}$.

Having the value of Weibull factor $b_{i n}$, the Weibull factor $a_{i n}$ can be calculated in terms of the values of the average overtopping discharge with Eq. (17) (Hughes and Nadal, 2009). Fig. 14 plots the fitted $a_{i n}$ versus estimated $a_{i n}$ from Eqs. (24) and (17) for all the tests, and a better agreement is shown. 


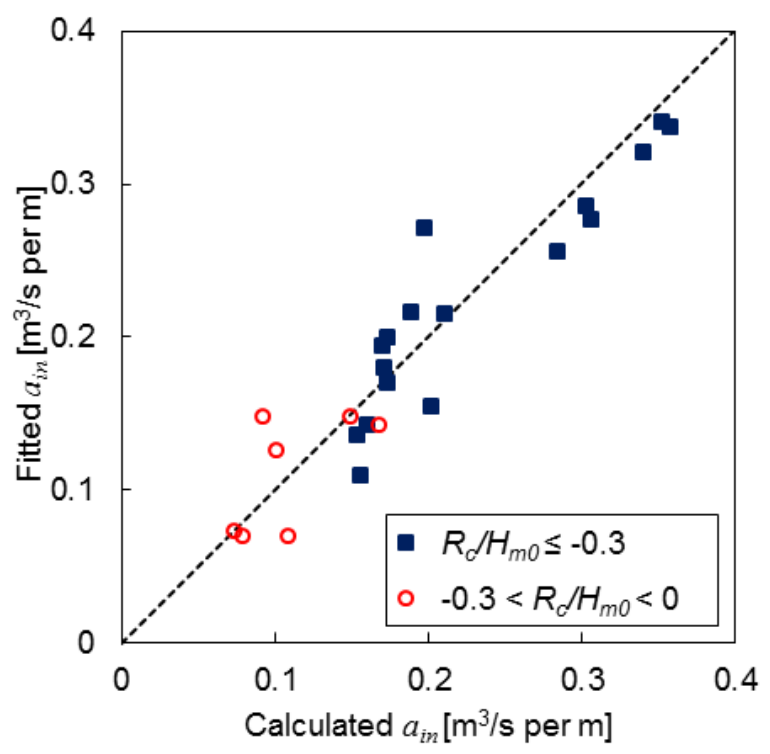

Fig. 14. Comparison of fitted and estimated Weibull factor $a_{i n}$ from Eqs. (24) and (17).

\section{Conclusions}

The overtopping pattern, distribution of individual overtopping volumes, and distribution of instantaneous overtopping discharge of wave overtopping under negative freeboard have been investigated based on the results of full-scale flume tests and a comparison with existing equations of Hughes and Nadal (2009).

Four wave overtopping patterns can be observed during the full-scale tests: (a) plunging breakers on seaward-side slope; (b) plunging breakers on crest; (c) waves passing smoothly without breaker; and d) waves passing smoothly with spilling breakers. Patterns (a) and (b) are summarized as breaking passing, which have more broken wave front and turbulent mix of water flow, and have more erosion effects on the levee crest. Patterns (c) and (d) are summarized as 
smooth passing, which have less broken wave front and thus induce large wave front velocity and more erosion effects on landward-side slope. The probabilities of occurrence of breaking passing and smooth passing are affected by the relative freeboard and can be estimated by Eq. (19).

Two-parameter Weibull distribution as shown by Eq. (7) is used to represent the distribution of individual overtopping volumes. Equations are given in Eq. (20) to estimate the shape factor $b$ in the ranges of $-0.3 \leq R_{c} / H_{m 0}<0$ and $R_{c} / H_{m 0}<-0.3$ respectively. The distribution trend of $b$ estimated from Eq. (20) is similar to that of Hughes and Nadal (2009). However, Eq. (20) gives better estimates of $b$, especially for the low discharge cases, in which the two distributions trends are distinguished clearly in different ranges of $R_{c} / H_{m 0}$. The distribution of fitted scale factor $a$ from the full-scale tests is close, but slightly higher than the estimation of Hughes and Nadal (2009) given in Eq. (14). The slight deviation may be explained by the model and measurement effects, resulting from different modelling techniques and measurement equipment in different tests, as stated in the EurOtop manual (Pullen et al., 2007). Based on Eq. (14), a modified equation is given tentatively in Eq. (21). The mean and maximum individual volume can be estimated with the calculated Weibull factors $a$ and $b$. The calculated mean individual volumes fit the measurements well, while the calculated maximum individual overtopping volumes is mediocre but acceptable.

Two-parameter Weibull distribution is also used to represent the distribution of instantaneous overtopping discharge. The fitted values of Weilbull shape factor $b_{\text {in }}$ from full-scale tests were compared to that of the 25-to-1 tests of Hughes and Nadal (2009), and deviation can be found. 
The obvious deviation may also be explained by the model and measurement effects in different tests. New equation to estimate $b_{\text {in }}$ is given in Eq. (24) based on full-scale test results. With the calculated value of $b_{i n}$, the Weibull scale factor $a_{i n}$ can be calculated by Eq. (17).

In this paper, a better knowledge on the distribution of wave overtopping volume and instantaneous overtopping discharge under negative freeboard is derived. However, it should be noted that the conclusions and equations presented in this paper are based on the measurements of full-scale flume tests with a seaward-side slope of 1:4.25, and the equations may not be applicable for levees having different seaward-side slopes.

\section{Acknowledgements}

We sincerely thank the supports from the National Natural Science Foundation of China (51309092), the Natural Science Fund for Colleges and Universities in Jiangsu Province (BK20130833), the Fundamental Research Funds for the Central Universities (2013B03414), and the Department of Homeland Security-sponsored Southeast Region Research Initiative (SERRI) at the Department of Energy's Oak Ridge National Laboratory. Thanks are also expressed to 2 reviewers for their works. The reviewers' comments are very helpful to improve this manuscript.

\section{References}


Besley, P., 1999. Wave overtopping of seawalls. Design and Assessment Manual. R\&D Technical Report W178. HR Wallingford. ISBN: 185705069 X.

Franco, L., de Gerloni, M., van der Meer, J.W., 1994. Wave overtopping on vertical and composite breakwaters. Coast. Eng. Proc. 24, 1030-1044.

Henderson, F.M., 1966. Open channel flow. New York, NY: MacMillian Publishing Co., Inc.

Hughes, S.A., Nadal, N.C., 2009. Laboratory study of combined wave overtopping and storm surge overflow of a levee. Coast. Eng. 56 (3), 244-259.

Hughes S.A., Thornton, C.I., Van der Meer, J.W., Scholl, B.N., 2012. Improvements in describing wave overtopping processes. Coast. Eng. Proc. 33, waves-35.

IPCC (International Panel on Climate Change), 2007. Climate change 2007: The physical science basis. In: Solomon, S.; Qin, D.; Manning, M.; Chen, Z.; Marquis, M.; Averyt, K.B.; Tignor, M., and Miller, H.L. (eds.), Contribution of Working Group I to the Fourth Assessment Report of the Intergovernmental Panel on Climate Change. Cambridge, United Kingdom: Cambridge University Press.

Kindsvater, C.E., 1964. Discharge characteristics of embankment-shaped weirs. Water-Supply Paper 1617-A. Washington, DC: U.S. Geological Survey.

Li, L., Pan, Y., Amini, F., Kuang, C.P., 2012. Full scale study of combined wave and surge overtopping of a levee with RCC strengthening system. Ocean Eng. 54 (1), 70-86.

Li, L., Pan, Y., Amini, F., Kuang, C.P., Briaud, J.L., 2014. Erosion resistance of HPTRM strengthened levee from combined wave and surge overtopping. Geotech. Geol. Eng. 32(4), 847-857. 
Lykke Andersen, T., Burcharth, H.F., Gironella, X., 2011. Comparison of new large and small scale overtopping tests for rubble mound breakwaters. Coast. Eng. 58 (4), 351-373.

Mansard, E.P.D., Funke, E.R., 1980. The measurement of incident and reflected spectra using a least square method. Coast. Eng. Proc. 17, 154-172.

Nørgaard, J.Q.H., Lykke Andersen, T., Burcharth, H.F., 2014. Distribution of individual wave overtopping volumes in shallow water wave conditions. Coast. Eng. 83, 15-23.

Pan, Y., Li, L., Amini, F., Kuang, C.P., 2013a. Full-Scale HPTRM-Strengthened Levee Testing under Combined Wave and Surge Overtopping Conditions: Overtopping Hydraulics, Shear Stress, and Erosion Analysis. J. Coastal Res. 29 (1), 182-200.

Pan, Y., Li, L., Amini, F., Kuang, C.P., 2013b. Influence of Three Levee-Strengthening Systems on Overtopping Hydraulic Parameters and Hydraulic Equivalency Analysis between Steady and Intermittent Overtopping. J. Water. Port Coast. Ocean Eng. ASCE 139 (4), 256-266.

Pullen, T., Allsop, N.W.H., Bruce, T., Kortenhaus, A., Schüttrumpf, H., van der Meer, J.W., 2007. EurOtop: Wave overtopping of sea defences and related structures: Assessment Manual. www.overtopping-manual.com.

Rao, X., Li, L., Amini, F., Tang, H., 2012. Smoothed particle hydrodynamics modeling of combined wave and surge overtopping and hydraulic erosion of an articulated concrete block-strengthened levee system. J. Coastal Res. 28(6), 1500-1511.

Reeve, D.E., Soliman, A., Lin, P.Z., 2008. Numerical study of combined overflow and wave overtopping over a smooth impermeable seawall. Coast. Eng. 55 (2), 155-166.

Van der Meer, J.W., Janssen, J.P.F.M., 1994. Wave run-up and wave overtopping at dikes and 
revetments. Delft Hydraulics.

Victor, L., van der Meer, J.W., Troch, P., 2012. Probability distribution of individual wave overtopping volumes for smooth impermeable steep slopes with low crest freeboards. Coast. Eng. 64, 87-101.

Yuan, S., Li, L., Amini, F., Tang, H., 2014a. Numerical study of turbulence and erosion of an HPTRM strengthened levee under combined storm surge overflow and wave overtopping. J. Coastal Res. 30(1), 142-157.

Yuan, S., Li, L., Amini, F., Tang, H., 2014b. Turbulence measurement of combined wave and surge overtopping over a full scale HPTRM strengthened levee. J. Water. Port Coast. Ocean Eng. ASCE 140, 04014014. 